\title{
First insights on the mitochondrial genetic variability of Lightiella magdalenina (Crustacea), the sole Mediterranean cephalocarid species
}

\author{
Daria Sanna ${ }^{*}$, Alberto Addis, Fabio Scarpa, Francesca Fabiano, Marcella Carcupino and Paolo Francalacci
}

\begin{abstract}
Background: Here we report the first insight into the mitochondrial (Cytochrome c Oxidase subunit I - COI and Cytochrome b - Cyt b) genetic variation of the only Mediterranean cephalocarid Lightiella magdalenina.

Findings: $\mathrm{COI}$ sequences provide a scenario of low intraspecific variability, while significant genetic divergence occurs between L. magdalenina and L. incisa. Interestingly, Cyt b sequences reveal a higher degree of intraspecific variability, with no shared haplotypes between the sites considered.

Conclusions: In the future, $\mathrm{COI}$ and Cyt b molecular markers could be used as valuable tools to shed new light into the extant species within the genus Lightiella thus providing molecular support to the taxonomical identifications carried out on a morphological basis.
\end{abstract}

Keywords: Lightiella magdalenina, Mitochondrial genes, Sequencing, Cephalocarida, Mediterranean Sea

\section{Findings}

\section{Background}

Cephalocarids are a class of small benthic crustaceans distributed from the intertidal zone to a depth of approximately $1550 \mathrm{~m}$ [1]. They have been recently considered to be phylogenetically related to the class Remipedia (Crustacea), using both nuclear [2] and mitochondrial [3] markers. Currently, only one order (Brachypoda) has been described with one family (Hutchinsoniellidae) containing twelve species belonging to five genera (Hutchinsoniella, Lightiella, Sandersiella, Chiltoniella, Hampsonellus) [4].

The genus Lightiella harbours the greatest number of species (five) and the largest distribution (for a review see [4]), with L. serendipita Jones, 1961 reported from San Francisco Bay, California, L. incisa Gooding, 1963 from the Gulf of Mexico and Caribbean Sea, L. monniotae Cals \& Delamare Deboutteville, 1970 from New Caledonia, L. floridana McLaughlin, 1976 from the western coast of Florida, and L. magdalenina Carcupino, Floris, Addis, Curini-Galletti, Castelli, 2006 from Sardinia. However, each species of this genus presents a very restricted

\footnotetext{
* Correspondence: darsanna@uniss.it

Dipartimento di Scienze della Natura e del Territorio - Sezione di Zoologia, Archeozoologia e Genetica - Università di Sassari, Via Francesco Muroni 25, 07100 Sassari, Italy
}

(c) 2014 Sanna et al.; licensee BioMed Central Ltd. This is an Open Access article distributed under the terms of the Creative Commons Attribution License (http://creativecommons.org/licenses/by/2.0), which permits unrestricted use, distribution, and reproduction in any medium, provided the original work is properly credited. The Creative Commons Public Domain Dedication waiver (http://creativecommons.org/publicdomain/zero/1.0/) applies to the data made available in this article unless otherwise stated. distribution, with the exception of L. incisa, which is reported to populate the entire Caribbean Sea and the Gulf of Mexico.

The five species belonging to the genus Lightiella show limited morphological differentiation [4,5]. Given the limited number of specimens used for taxonomical classification, their detailed external morphology is often incomplete e.g. [6]. In light of these considerations, Olesen et al. [4] advise that the genus needs an urgent overhaul. In particular, these authors suggest that the species richness within the whole Cephalocarida class may have been overestimated. A molecular taxonomic approach could address this problem although molecular data are so far available for only three cephalocarid species: Hutchinsoniella macracantha, L. magdalenina, and $L$. incisa. Mitochondrial and nuclear genes sequences (see [7-14] for details) are available for $H$. macracantha. Sequences of mitochondrial genes are known for $L$. magdalenina (see [15] for details), while mitochondrial and nuclear gene sequences are known for L. incisa (see [3] for details).

The species Lightiella magdalenina is the only cephalocarid reported in the Mediterranean and is only found so far from its type locality in La Maddalena Archipelago (Sardinia, Italy) (see [5] for details). Cladistic analysis 
based on external morphology [5] suggest that L. magdalenina is more closely related to the Caribbean species L. incisa and L. floridana than to the Pacific Ocean species L. serendipita (California, Pacific Ocean).

In this study, we provide the first preliminary insight into the genetic variation of the isolated Mediterranean cephalocarid L. magdalenina using sequences of the mitochondrial DNA Cytochrome $c$ Oxidase subunit I (COI) and Cytochrome b (Cyt b) coding genes from the two close Mediterranean sites where this species is found.

We also provide new specific primers for the COI gene. Results obtained were compared with data from other species of cephalocarids and remipeds.

\section{Methods}

Eighteen specimens (10 adults and 8 larvae) of Lightiella magdalenina were collected at a depth of 15-25 m from muddy sand of the southern shore of La Maddalena Archipelago (Sardinia, Italy) (Figure 1). Sampling was carried out, using SCUBA, during the 2007-2011 spring/ summer seasons. We analysed specimens from the type locality (Punta San Giorgio) and from an adjacent site (Isolotto Roma) (approximately $600 \mathrm{~m}$ farther), both characterised by bottoms with Posidonia oceanica and Caulerpa racemosa (see Figure 1 for details). No individuals of L. magdalenina were found when sampling campaigns were carried out in other eight sites from five western Mediterranean localities in northern Sardinia and southern France (see Figure 1 for details).

DNA was extracted from whole specimens by means of the QIAGEN ${ }^{\circledR}$ DNeasy Tissue kit (Hilden, Germany). DNA concentration was estimated through fluorometric measurements (average value per sample: $10 \mathrm{ng} / \mu \mathrm{L}$ ).

Since COI universal primers for marine invertebrates [16] did not result in good quality sequences, the COI region was amplified using specific primers designed in the present study (L: 5'-gttactctggggggattcgga-3' and H: 5'-ggccaaaata gaagaaaccccagcta-3'). Universal primers reported by Boore and Brown [17] (L: 5'-ggwtaygtwytwccwtgrggwcarat-3' and $\mathrm{H}$ : $5^{\prime}$-gcrtawgcraawarraartaycaytcwgg-3') were used for the Cyt b gene. Attempts to design new specific primers for this region, without critically affecting the quality of the amplified fragment, failed. Each $25 \mu \mathrm{L}$ PCR mixture contained approximately $50 \mathrm{ng}$ of total genomic DNA, $0.4 \mu \mathrm{M}$ of each primer, and 2.5 U of EuroTaq DNA Polymerase (Euroclone ${ }^{\circ}$, Italy) in a reaction mix prepared according to the manufacturer's instructions. The $\mathrm{MgCl}_{2}$ concentration was set at $2.5 \mathrm{mM}$.

PCR amplification was performed with an initial denaturation step of $2 \mathrm{~min}$ at $94^{\circ} \mathrm{C}$, followed by 35 cycles of $1 \mathrm{~min}$ at $94^{\circ} \mathrm{C}, 1 \mathrm{~min}$ and $30 \mathrm{sec}$ at $49^{\circ} \mathrm{C}$, and $1 \mathrm{~min}$ and $30 \mathrm{sec}$ at $72^{\circ} \mathrm{C}$. The final elongation step was for $5 \mathrm{~min}$ at $72^{\circ} \mathrm{C}$ with a final cooling at $4^{\circ} \mathrm{C}$. In all experiments, negative controls and replicates were included. Electrophoretic runs were carried out at $4 \mathrm{~V} / \mathrm{cm}$ for $20 \mathrm{~min}$ in $2 \%$ agarose gels prepared using $0.5 \times \mathrm{TBE}$ buffer. The gels were then stained with ethidium bromide $(10 \mathrm{mg} / \mathrm{mL})$.

PCR products were purified with ExoSAP-IT (USB Corporation ${ }^{\circ}$ USA) and sequenced using an external sequencing core service (Macrogen Inc. ${ }^{\circ}$, Europe). Sequences were aligned using Clustal W [18], implemented in the BioEdit 7.1.3.0 software package [19], and deposited in GenBank [COI:JX013538-JX013555; Cyt b:JX013556JX013565].

In order to characterise genetic variation among individuals in both populations, the number of polymorphic sites $(S)$, of haplotypes $(H)$, the estimates of haplotype diversity $(h)$, and nucleotide diversity $(\pi)$, were computed using the software DnaSP 5.10 [20].

Genetic relationships among haplotypes were investigated by constructing a median-joining network using the software Network 4.6 [http://www.fluxus-engineering. $\mathrm{com} / \mathrm{]}$. In the absence of random recurrent polymorphisms across the whole dataset, an identical weight (10) was given to all mutations to preserve the original genetic information. We ran the Maximum Parsimony (MP) calculation post-processing option to delete all superfluous median vectors and links that were not contained in the shortest trees of the network. For the COI gene, the analysis was performed by adding also the sequences of two other cephalocarids, Lightiella incisa [GenBank: GQ328968] and Hutchinsoniella macracantha [GenBank: AF370852]. In addition, two sequences, representative of the two families of the class Remipedia, Pleomothra apletocheles (Godzilliidae) [GenBank:GU067682] and Speleonectes tulumensis (Speleonectidae) [GenBank:NC_ 005938], were included in the analysis as outgroups. For the Cyt b gene, the analysis was carried out including the cephalocarid Hutchinsoniella macracantha [GenBank: AY456189] plus the remipede Speleonectes tulumensis [GenBank:NC_005938] as outgroup.

\section{Results}

\section{COI analysis}

Eighteen individuals were sequenced and a 216 base pair (bp) alignment was obtained. A previously published sequence [GenBank:EU530536] [15] belonging to an individual from Punta San Giorgio (see Table 1 for details) was added to the dataset. All 19 specimens shared the same haplotype, except one specimen from Isolotto Roma [GenBank:JX013545], bearing a single non-synonymous transversion ( $G$ to $C$ ). Indices of genetic variation are reported in Table 1.

Results obtained by the median-joining network analysis (Figure 2a) provided support for strong genetic differentiation between L. magdalenina and L. incisa. Sixteen (for 


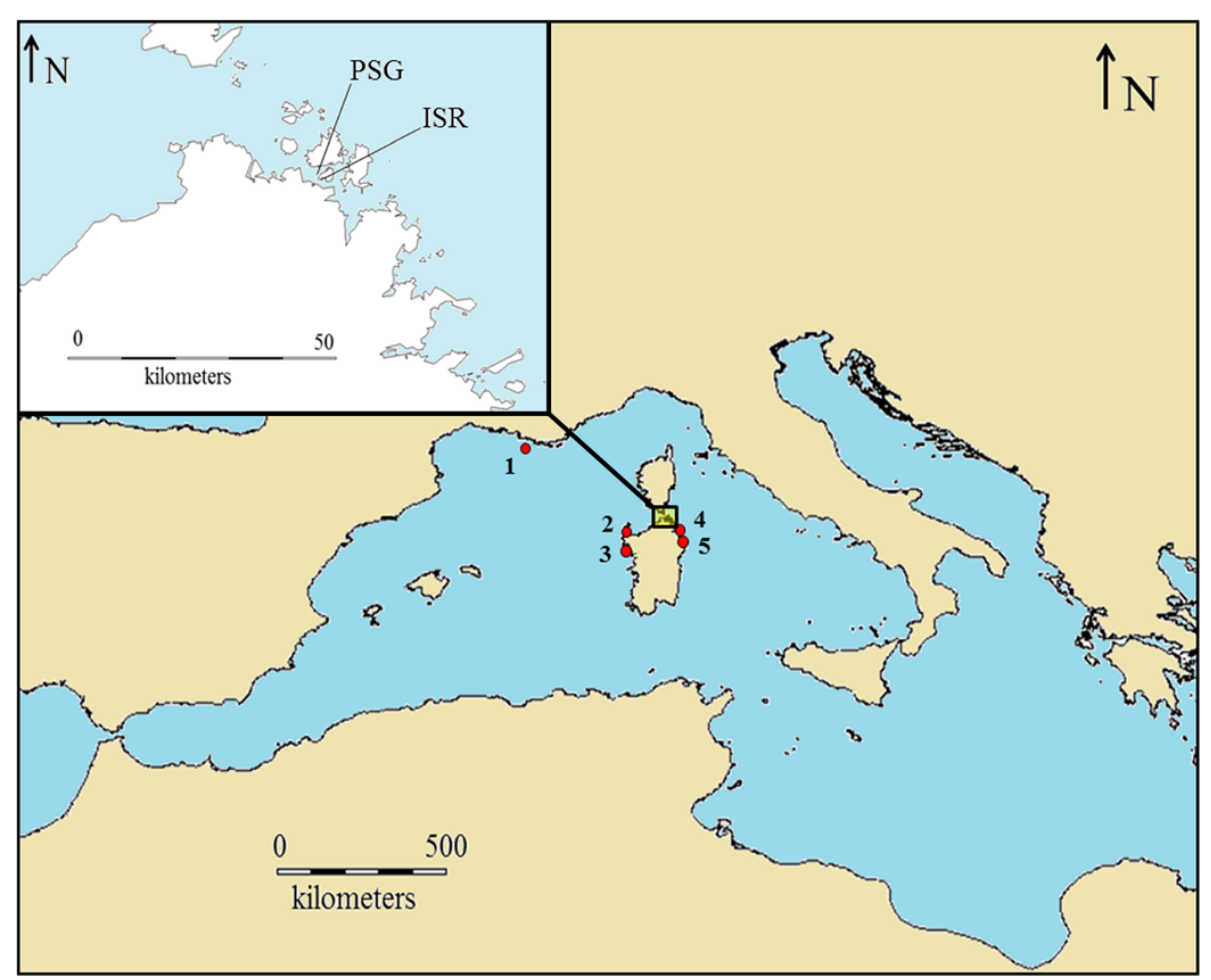

Figure 1 Map of the sampling sites. Numbers indicate western Mediterranean zones where no individuals of Lightiella magdalenina were found during sampling campaigns. 1: Marseille (3 sites); 2: Stintino (1 site); 3: Alghero (2 sites); 4: Golfo Aranci (1 site); 5: Cala Finanza - Loiri Porto San Paolo (1 site). The boxed area in the map is depicted in further detail in the outset. PSG: Punta San Giorgio (41 $\left.11^{\prime} 23.9^{\prime \prime} \mathrm{N} ; 09^{\circ} 23^{\prime} 54.7^{\prime \prime} \mathrm{E}\right)$;

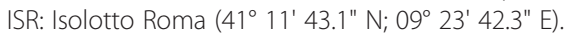

L. magdalenina) and 12 (for L. incisa) point mutations represent the apomorphic polymorphisms of the two species. Twenty-seven point mutations separated H. macracantha from the group including L. magdalenina and L. incisa.

\section{Cyt $b$ analysis}

As a possible consequence of the limited homology between the universal primers [17] and the annealing region in our specimens, scorable Cyt b sequences were

Table 1 Estimates of genetic diversity for COI and Cyt b gene fragments

\begin{tabular}{lcccccc}
\hline Sample & N & bp & S & $\boldsymbol{H}$ & $\boldsymbol{h}$ & $\boldsymbol{\pi}$ \\
\hline \multicolumn{7}{c}{ COI } \\
Punta San Giorgio & 5 & 216 & 0 & 1 & 0.000 & 0.00000 \\
Isolotto Roma & 14 & 216 & 1 & 2 & 0.143 & 0.00066 \\
Total & 19 & 216 & 1 & 2 & 0.105 & 0.00049 \\
& \multicolumn{7}{c}{ Cyt b } \\
Punta San Giorgio & 3 & 348 & 8 & 2 & 0.667 & 0.01533 \\
Isolotto Roma & 7 & 348 & 2 & 2 & 0.476 & 0.00274 \\
Total & 10 & 348 & 10 & 4 & 0.733 & 0.00888 \\
\hline N: samp & &
\end{tabular}

$\mathrm{N}$ : sample sizes; bp: base pairs; $S$ : number of polymorphic sites; $H$ : number of haplotypes; $h$ : haplotype diversity; $\pi$ : nucleotide diversity. obtained for only ten individuals (three from Punta San Giorgio and seven from Isolotto Roma). The already published Cyt b sequence [GenBank:EU530537] was not included in the dataset since a BLAST search revealed highest similarity with Saprolegnia ferax (a fungus belonging to the family Saprolegniaceae) (81\% identity, coverage $87 \%$ ) and indicated a possible fungal contamination of this sample. A 348 bp long alignment was obtained. In total, four haplotypes were detected. Values of genetic diversity were higher than those obtained for the COI gene (Table 1). No haplotypes were shared between Punta San Giorgio and Isolotto Roma samples. All of the ten polymorphic sites retrieved were biallelic with seven synonymous substitutions. Eight transversions and two transitions occurred.

The median-joining network analysis (Figure 2b) revealed a well-defined divergence, supported by 85 to 125 point mutations (this pattern contains a cycle with three median vectors separated from each other by 39 mutational steps) between L. magdalenina and H. macracantha. Within the L. magdalenina group, the most common haplotype was exclusive of individuals from Isolotto Roma, while two haplotypes belonging to Punta San Giorgio and one from Isolotto Roma diverged by two to five point mutations from the root sequence. 


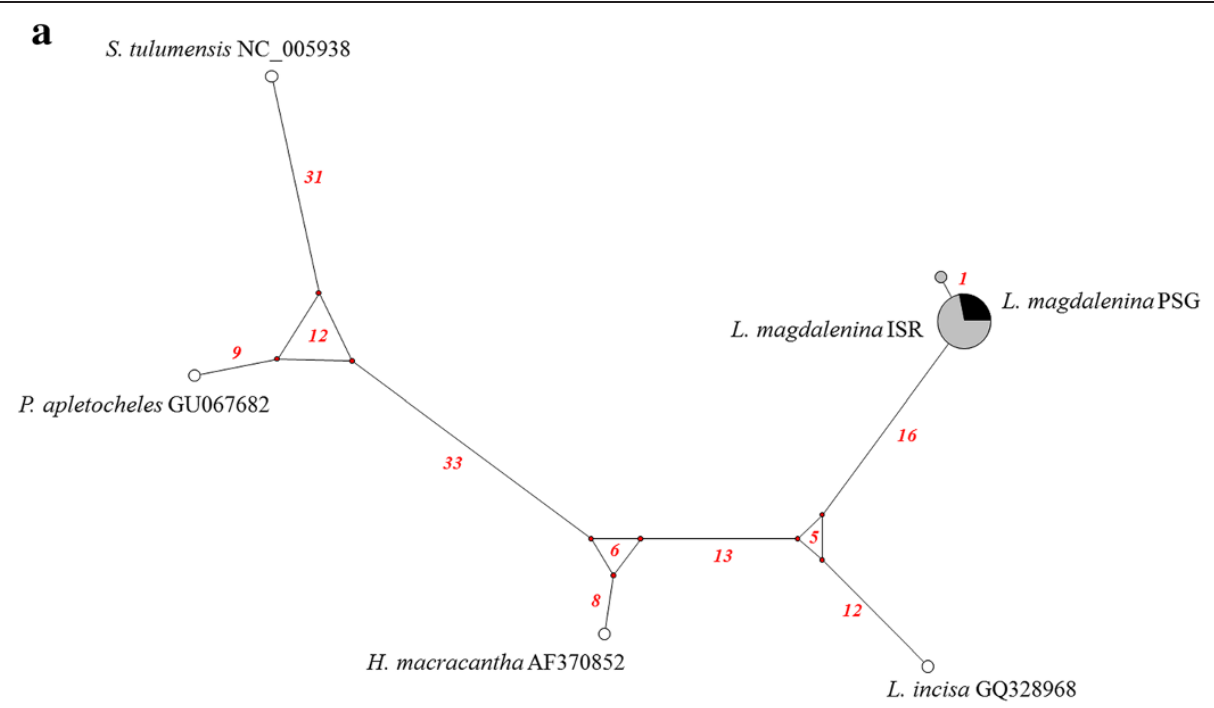

b

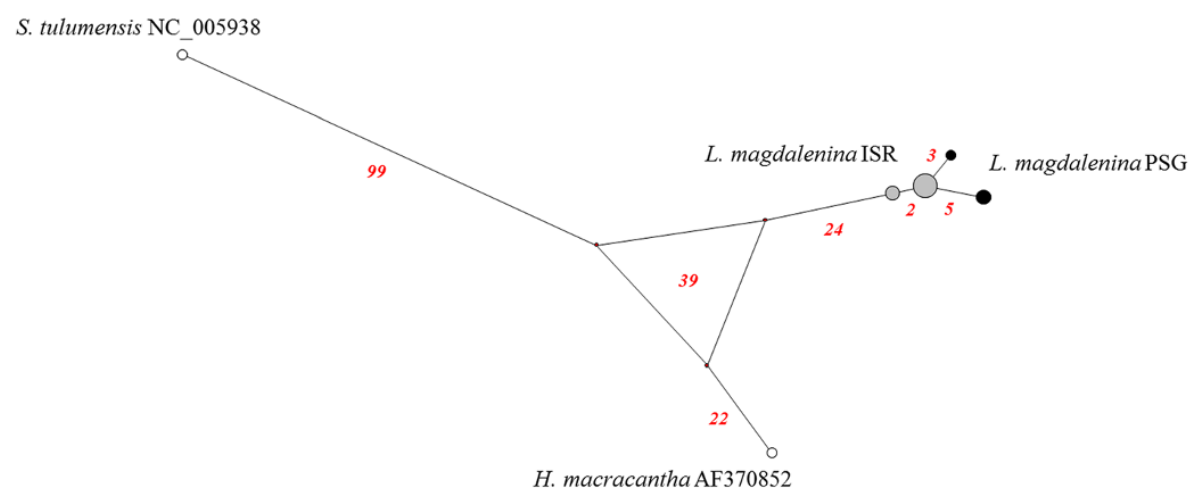

Figure 2 Median-joining network showing relationships among Lightiella magdalenina haplotypes and other cephalocarids and remipedes. Median-joining network based on COI (a) and Cyt b (b) datasets. The number of point mutations is reported along the lines connecting haplotypes. Rings on the nodes show median vectors, representing hypothetic connecting sequences, calculated with the maximum parsimony method. Pie sizes are proportional to the absolute frequency of each haplotype/sequence. Due to graphical representation issues the length of edges connecting L. magdalenina haplotypes is not exactly proportional to the number of mutating positions between haplotypes. The sample codes are reported in Figure 1. For species abbreviations, refer to the main text.

\section{Discussion}

Five decades after the first description of Cephalocarida [21] our knowledge of this taxon is still limited, especially for species other than Hutchinsoniella macracantha. The present work evidences that if COI universal primers [16] fail, even a $216 \mathrm{bp}$ long internal portion (amplified by the new primers provided here) of the widely used $710 \mathrm{bp}$ long Folmer [16] region can be used for the taxonomic identification of the species belonging to the genus Lightiella. Consistently, previous studies [22,23] showed that partial fragments of the Folmer region of about or less than two hundred bp may correctly assess phylogenetic/phylogeographic traits of the species. In such a context, our preliminary analyses provide molecular support to the morphology-based distinction reported between L. magdalenina and L. incisa [5].
Sequencing of the Cyt $\mathrm{b}$ gene, performed on L. magdalenina specimens, showed higher values of intraspecific genetic variability than the COI gene. Indeed, the absence of shared Cyt b haplotypes between L. magdalenina specimens from the two neighbouring sites sampled in this study is consistent with the possible occurrence of two distinct populations. In spite of the close geographical proximity of the two sites (only $600 \mathrm{~m}$ apart), the isolation can be explained by restricted population size [24] together with a low dispersion capacity of the species [1]. In fact, L. magdalenina, lacks a high-dispersal phase, given that both larval stages and adults show a strictly benthic lifestyle $[1,25]$. However, it should be taken into consideration that this pattern could be affected by the small number of samples from Punta San Giorgio (three individuals), thus preventing supported inferences. 
In conclusion, this study reports the first data on the genetic variation of a cephalocarid species, providing a preliminary survey on the mitochondrial variability of the only Mediterranean species, L. magdalenina.

The high level of interspecific genetic divergence reported between L. magdalenina and L. incisa, using the COI gene, offers molecular support to previous morphological analysis [5], allowing to consider this marker as a valuable tool for molecular taxonomic assays within the genus Lightiella. On the other hand, if confirmed by further analysis on a larger number of samples, the estimates of intraspecific variation based on the Cyt $b$ gene for L. magdalenina suggest the possible use of this marker for assessing the phylogeographic patterns of the species.

These results highlight the importance of performing joint (COI and Cyt b) molecular analyses in cephalocarids for further taxonomic revision of the genus Lightiella and population genetic surveys.

\section{Competing interests}

The authors declare that they have no competing interests.

\section{Authors' contributions}

DS designed the study, conceived and designed the experiments, performed the molecular and statistical analysis and drafted the manuscript. AA participated in the collection of specimens and drafting of the manuscript. FS participated in the molecular analysis and revision of the manuscript. FF participated in collection of specimens and revision of the manuscript. MC and PF conceived the study and participated in its design, coordination, and drafting; also contributed reagents/materials. All authors read and approved the final manuscript.

\section{Acknowledgements}

We thank La Maddalena Archipelago National Park and especially Mr. Mirko Ugo for logistical and technical support during the collection of specimens. We also thank the two anonymous referees for their comments and criticisms which greatly helped in improving the MS. This work was supported by the Regione Autonoma della Sardegna with funds from Operative Program FSE 2007-2013 L.R.7/2007 "Promozione della ricerca scientifica e dell'innovazione tecnologica in Sardegna" (grant to AA), by MURST (Ministero per I'Università e la Ricerca Scientifica e Tecnologica) ex-60\% (grant to PF), and by Fondazione Banco di Sardegna, 2013 (grant to MC).

Received: 27 September 2013 Accepted: 22 January 2014

Published: 13 May 2014

\section{References}

1. Addis A, Biagi F, Floris A, Puddu E, Carcupino M: Larval development of Lightiella magdalenina (Crustacea, Cephalocarida). Mar Biol 2007, 152:733-744.

2. Regier JC, Shultz JW, Zwick A, Hussey A, Ball B, Wetzer R, Martin JW, Cunningham CW: Arthropod relationships revealed by phylogenomic analysis of nuclear protein-coding sequences. Nature 2010, 463:1079-1083.

3. Koenemann S, Jenner RA, Hoenemann M, Stemme T, von Reumont BM: Arthropod phylogeny revisited, with a focus on crustacean relationships. Arthropod Struct Dev 2010, 39:88-110.

4. Olesen J, Haug JT, Maas A, Waloszek D: External morphology of Lightiella monniotae (Crustacea, Cephalocarida) in the light of Cambrian 'Orsten' crustaceans. Arthropod Struct Dev 2011, 40:449-478.

5. Carcupino M, Floris A, Addis A, CA, Curini-Galletti M: A new species of the genus Lightiella: the first record of Cephalocarida (Crustacea) in Europe. Zool J Linn Soc-Lond 2006, 148:209-220.

6. Cals $P$, Delamare Deboutteville $C$ : Une nouvelle espèce de Crustacé Céphalocaride de l'hémisphère austral. CR Acad Sci III-Vie 1970, 270:2444-2447.
7. Spears T, Abele LG: Crustacean phylogeny inferred from $18 \mathrm{~S}$ rDNA. In Arthropod Relationships. 1st edition. Edited by Fortey RA, Thomas RH. London: Chapman and Hall; 1998:169-187.

8. Colgan DJ, McLauchlan A, Wilson GDF, Livingston SP, Edgecombe GD, Macaranas J, Cassis G, Gray MR: Histone H3 and U2 snRNA DNA sequences and arthropod molecular evolution. Aust J Zool 1998 46:419-437.

9. Regier JC, Shultz JW: Molecular phylogeny of arthropods and the significance of the Cambrian "explosion" for molecular systematics. Am Zool 1998, 38:918-928.

10. Regier JC, Shultz JW: Elongation factor-2: A useful gene for arthropod phylogenetics. Mol Phylogenet Evol 2001, 20:136-148.

11. Shultz JW, Regier JC: Phylogenetic analysis of arthropods using two nuclear protein-encoding genes supports a crustacean + hexapod clade. P Roy Soc B-Biol Sci 2000, 267:1011-1019.

12. Giribet G, Edgecombe GD, Wheeler WC: Arthropod phylogeny based on eight molecular loci and morphology. Nature 2001, 413:157-161.

13. Lavrov DV, Brown WM, Boore JL: Phylogenetic position of the Pentastomida and (pan)crustacean relationships. P Roy Soc B-Biol Sci 2004, 271:537-544.

14. Richter S, Olesen J, Wheeler WC: Phylogeny of Branchiopoda (Crustacea) based on a combined analysis of morphological data and six molecular loci. Cladistics 2007, 23:301-336.

15. Sanna D, Addis A, Carcupino M, Francalacci P: Molecular data on two mitochondrial genes of a newly discovered crustacean species (Lightiella magdalenina, Cephalocarida). J Mar Biol Assoc UK 2010, 90:827-829.

16. Folmer O, Black M, Hoeh W, Lutz R, Vrijenhoek R: DNA primers for amplification of mitochondrial cytochrome $\mathrm{c}$ oxidase subunit I from diverse metazoan invertebrates. Mol Mar Biol Biotechnol 1994, 3:294-299.

17. Boore JL, Brown WM: Mitochondrial genomes of Galathealinum, Helobdella, and Platynereis: sequence and gene arrangement comparisons indicate that Pogonophora is not a phylum and Annelida and Arthropoda are not sister taxa. Mol Biol Evol 2000, 17:87-106.

18. Thompson JD, Higgins DG, Gibson TJ: CLUSTAL W: improving the sensitivity of progressive multiple sequence alignment through sequence weighting, position-specific gap penalties and weight matrix choice. Nucleic Acids Res 1994, 22:4673-4680.

19. Hall TA: BioEdit: a user-friendly biological sequence alignment editor and analysis program for Windows 95/98/NT. Nucl Acids Symp Ser 1999, 41:95-98.

20. Rozas J, Rozas R: DnaSP version 3: an integrated program for molecular population genetics and molecular evolution analysis. Bioinformatics 1999, 15:174-175.

21. Sanders HL: The Cephalocarida, a new subclass of Crustacea from Long Island Sound. Proc Natl Acad Sci USA 1955, 41:61-66.

22. Hajibabaei M, Smith MA, Janzen DH, Rodriguez JJ, Whitfield JB, Hebert PDN: A minimalist barcode can identify a specimen whose DNA is degraded. Mol Ecol Notes 2006, 6:959-964.

23. Sanna D, Lai T, Francalacci P, Curini-Galletti M, Casu M: Population structure of the Monocelis lineata (Proseriata, Monocelididae) species complex assessed by phylogenetic analysis of the mitochondrial Cytochrome $c$ Oxidase subunit I (COI) gene. Genet Mol Biol 2009, 32:864-867.

24. Addis A, Fabiano F, Delogu V, Carcupino M: Reproduction system morphology of Lightiella magdalenina (Crustacea, Cephalocarida): functional and adaptive implications. Invertebr Reprod Dev 2013, 57:142-155.

25. Sanders HL, Hessler RR: The larval development of Lightiella incisa Gooding (Cephalocarida). Crustaceana 1964, 7:81-97.

doi:10.1186/2241-5793-21-5

Cite this article as: Sanna et al: First insights on the mitochondrial genetic variability of Lightiella magdalenina (Crustacea), the sole Mediterranean cephalocarid species. Journal of Biological ResearchThessaloniki 2014 21:5. 